\title{
The moderating effect of self-confidence on the relationship between extraversion and subjective well-being
}

\author{
Hong Shao ${ }^{1, a}$, Bing Shi ${ }^{1, b}$, YuLiang Sun ${ }^{1, c}$ \\ ${ }^{1}$ School of Physical Education, Shaanxi Normal University, Shaanxi 710119, China; \\ a317918239@qq.com, b378833269@qq.com, c1010720@qq.com
}

Keywords: college students, extraversion, subjective well-being, self - confidence.

\begin{abstract}
The relationship between different personality tendencies, self-confidence and subjective well-being was explored on Shaanxi Normal University and Xidian University of 343 undergraduates. And questionnaires like Youth Self Confidence Inventory, Index of Subjunctive Weil-Being and a Chinese version of the Eysenck personality questionnaire (EPQ-RS) are deployed on the undergraduates. The following conclusions are drawn: (1) the internal and external inclination has significant predictive effect on self-confidence and subjective well-being. (2)self-confidence has a moderating effect on the relationship between the internal and external inclination and people's subjective well-being: in low self-confidence, internal and external inclination to the subjective well-being of a significant predictive role, in the case of high self-confidence, internal and external inclination to the subjective well-being of the predictive effect is not significant.
\end{abstract}

\section{Introduction}

With the development of positive psychology, subjective well-being has gradually received wide attention. Subjective well-being is a holistic, subjective evaluation of the quality of life on emotional and cognitive aspects. The evaluation is relatively stable. In the study of subjective well-being, personality is a very stable and powerful indicator [1]. Among them, the personality trait of extroversion is closely related to people's emotional activity, it will affect human's adaptability and subjective well-being. [2]. Extroversion is an important predictor of subjective well-being. At the same time, studies have shown that both internal and external inclinations are positively correlated with subjective well-being, and are shown in groups of different ages [3] [4].

Self-confidence is an individual's emotional assessment of oneself, a perception of their ability. In previous studies, it has been found that confidence has a significant predictive effect on subjective well-being. [5]

From the previous studies, we can find that both internal and external inclinations tended to be used to predict the subjective well-being, self-confidence to subjective well-being also have certain prediction effect, and it is widely believed that outgoing people are more confident than introverted people. Based on previous studies, this study added confidence as a variable, discussed whether extroversion had a significant predictive effect on confidence and subjective well-being. And if confidence has a moderating effect on the relationship between extroversion and subjective well-being.

This study proposed two hypotheses: (1) the internal and external inclination has significant predictive effect on self-confidence and subjective well-being. (2) self-confidence has a moderating effect on the relationship between extroversion and people's subjective well-being. 


\section{Methods}

\subsection{Participants}

Students from Shaanxi normal University and Xidian University were tested, and 343 college students were measured, including 155 females and 188 male students. The measurement method is combined with the online survey and send questionnaire.

\subsection{Measuring tools}

\subsubsection{Youth Self-Confidence Inventory}

The questionnaire was compiled by Zengchong Bi and Xiting Huang (2009). There are 33 questions in the questionnaire. The internal consistency reliability $\operatorname{Alpha}(\alpha)$ coefficient of the questionnaire was 0.92 , and each factor $\operatorname{Alpha}(\alpha)$ coefficient was between 0.72-0.82. The retest reliability coefficient of the questionnaire was 0.81 , and each factor was between 0.70 and 0.86 , with good reliability and validity. Scale uses the Likert5 level score. [6].

\subsubsection{Index of Well-Being, Index of General Affect, Campbell et al, 1976}

The scale includes the overall emotional index scale and the life satisfaction scale. The former consists of 8 items and the later consists of 1 project. The internal consistency reliability of the emotional index scale was 0.89 , the retest reliability was 0.43 , and the correlation coefficient of life satisfaction questionnaire was 0.55 . The scale is a 7 grade self-assessment questionnaire..

\subsubsection{A Chinese version of the Eysenck personality questionnaire. (EPQ-RSC)}

Chinese version (EPQ-RSC) personality inventory was revised by Mingyi Qian (2000). After years of verification, the reliability of the questionnaire is high. Questionnaire contains four subscales, extraversion (E), neuroticism (N), psychoticism (P), and hide scale (L), each subscales have 12 questions, using "is" or "no" to score. In this study, the extraversion (E) scale was chosen.

\subsection{Statistical Processing}

The original score of each dimension of each questionnaire was calculated and SPSS 22.0 software was used to analyze the collected data. Statistical methods: descriptive statistics, single factor variance analysis, correlation analysis, regression analysis, etc.

\section{Results}

\subsection{Gender effect}

In order to understand the he influence of gender on self-confidence and subjective well-being, the study take gender as the group variable, confidence and subjective well-being as the dependent variable, did an independent samples t-test, and the results indicate that the differences between gender in confidence and subjective well-being were not significant.

\subsection{Correlations between extraversion, confidence and subjective well-being}

To verify the relationship between extraversion, confidence and subjective well-being, we did a correlation analysis, about extraversion, self-confidence, and two dimensions of subjective well-being .The correlation matrix of extraversion, confidence and subjective well-being is obtained. (Table 1). 
Table 1 The correlation matrix of extraversion, confidence and subjective well-being( $\mathrm{N}=343)$

\begin{tabular}{|c|c|c|c|c|c|}
\hline & Extraversion & Self-confidence & $\begin{array}{c}\text { Index of } \\
\text { General } \\
\text { Affect } \\
\end{array}$ & $\begin{array}{c}\text { Index of } \\
\text { Well-Being }\end{array}$ & $\begin{array}{l}\text { Subjective } \\
\text { well-being }\end{array}$ \\
\hline Extraversion & 1 & & & & \\
\hline $\begin{array}{l}\text { Self-confiden } \\
\text { ce }\end{array}$ & $0.317 * * *$ & 1 & & & \\
\hline $\begin{array}{l}\text { Index of } \\
\text { General } \\
\text { Affect }\end{array}$ & $0.416^{* * *}$ & $0.404^{* * *}$ & 1 & & \\
\hline $\begin{array}{l}\text { Index of } \\
\text { Well-Being }\end{array}$ & 0.262 & $0.344^{* * *}$ & $\begin{array}{l}0.657 * * \\
*\end{array}$ & 1 & \\
\hline $\begin{array}{l}\text { Subjective } \\
\text { well-being }\end{array}$ & $0.365 * * *$ & $0.408 * * *$ & $\begin{array}{l}0.894 * * \\
*\end{array}$ & $0.925 * * *$ & 1 \\
\hline
\end{tabular}

Note. ${ }^{*} \mathrm{p}<0.05,{ }^{* *} \mathrm{p}<0.01,{ }^{* * *} \mathrm{p}<0.001$.

Results showed that extraversion have a significant effect on self-confidence, subjective well-being and the index of general affect. Confidence is significantly correlated with subjective well-being and two dimensions of subjective well-being.

\subsection{Moderating Effect of Self-confidence}

In order to understand the prediction effect of extraversion on confidence and subjective well-being, we take extraversion as independent variable, confidence and subjective well-being as the dependent variables, and then we did regression analysis respectively. The results showed that extraversion had a significant predictive effect on confidence and subjective well-being, and extraversion explained the $10.3 \%(\mathrm{~F}=39.055, \mathrm{P}<0.001)$ of the self-confident variation, and $12.9 \%$ of the subjective well-being variation $(\mathrm{F}=50.505, \mathrm{P}<0.001)$. ( see Table 2 )

Table 2 Regression analysis( $\mathrm{N}=343)$

\begin{tabular}{cllll}
\hline Variables & $\mathrm{R} 2$ & $\mathrm{~B}$ & $\mathrm{t}$ & Beta \\
\hline Self-confidence & 0.103 & 0.594 & $6.249^{* * *}$ & $0.321^{* * *}$ \\
Subjective well-being & 0.129 & 0.076 & $7.107^{* * *}$ & $0.359^{* * *}$ \\
\hline
\end{tabular}

If the relationship between the variable $\mathrm{X}$ and the variable $\mathrm{Y}$ is a function of the variable $\mathrm{Z}$, then $\mathrm{Z}$ is the regulating variable of the relationship between $\mathrm{X}$ and $\mathrm{Y}$, that is, the relationship between $\mathrm{X}$ and $\mathrm{Y}$ is affected by the third variable $\mathrm{Z}$. In order to test whether confidence can become a regulating variable between extraversion and subjective well-being, we take subjective well-being as the dependent variable, and then did a regression analysis between extraversion and subjective well-being, as well as a regression analysis between extraversion, self-confidence, extraversion $\times$ confidence and subjective well-being.

Table 3 Regulating function test (hierarchical regression)

\begin{tabular}{|c|c|c|c|c|}
\hline & Steps and variables & $\mathrm{F}$ & R2 & Beta \\
\hline First step & & $\begin{array}{l}49.674 * * \\
*\end{array}$ & $\begin{array}{l}0.226 * * \\
*\end{array}$ & \\
\hline & $\begin{array}{l}\text { self-confidence } \\
\text { extraversion }\end{array}$ & & & $\begin{array}{l}0.329 * * \\
* \\
0.254 * * \\
*\end{array}$ \\
\hline $\begin{array}{l}\text { Second } \\
\text { step }\end{array}$ & & $\begin{array}{l}35.231^{* *} \\
*\end{array}$ & $0.238^{*}$ & \\
\hline & $\begin{array}{l}\text { self-confidence } \\
\text { extraversion } \\
\text { self-confidence } \times \\
\text { extraversion }\end{array}$ & & & $-0.942 *$ \\
\hline
\end{tabular}


From table 3, we can find that the main effect of self-confidence and extraversion on the subjective well-being were significantly, at the same time, the interaction of the two variables was significant (R2 change to 0.012, F change to 5.14, p < 0.05), suggesting that confidence has significant moderating effect to the relationship between extraversion and subjective well-being. Among them, the regression coefficient of interaction effect between confidence and extroversion was significant (Beta $=-0.942, \mathrm{t}=-2.267, \mathrm{p}<0.05)$.

To clearly reveal the relationship between extraversion and subjective well-being in the different confidence levels, we divided the confidence into high confidence (one standard deviation above average) and low confidence (below average one standard deviation), in both cases we did regression analysis between extraversion and subjective well-being respectively. The results showed that, under the high confidence level, extraversion did not predict the subjective well-being (Beta=0.232, $\mathrm{P}>0.01$ ). In low confidence level, the prediction of extraversion to subjective well-being was significant (Beta=0.596, $\mathrm{P}<0.001)$.

\section{Summary}

The subjective well-being of extroverted students was significantly higher than that of introverted students. The overall happiness of college students is positively correlated with E score. E points higher people is particularly more outgoing, more sociable, and more eager for excitement and adventure, and easy to have emotional impulse, that personality characteristics of college students can experience more positive emotions, and more outgoing personality allows them to get along well with others, and thus the cognitive evaluation of life quality is higher, has higher subjective well-being level. Furthermore, extroversion and neuroticism provide the primary link between personality and subjective well-being.

Consistent with previous studies, the prediction function of the internal and external inclination on the subjective well-being is significant. If participants get high scores on the extraversion (E), that means they are more confident, have stronger subjective well-being, and the regulation effect of self confidence in the relationship between the internal and external inclination and subjective well-being is remarkable.

The innovation of this study lies in it validates one thing,: people always think outgoing people must be more confidence than the introverted people, and the results from regression analysis proved that the self-confidence has a moderating effect on the relationship between the internal and external inclination and people's subjective well-being, at the same time this paper discusses if people who are in love are more confident than those who are not, and also stronger experienced than those who are not in love on subjective well-being. On the basis of verifying the conclusions of previous literatures, the variable of confidence is added, which comprehensively explores the relationship between the internal and external inclination and self-confidence of college students and subjective well-being.

The deficiency of this study is that subjects group is not strongly representative, all participants are from two universities only, although these students come from different places, but the generalization and universality of these subjects is restricted, and also may not have powerful popularization.

From the data processing results we can infer that: (1) the internal and external inclination has significant predictive effect on self-confidence and subjective well-being. (2) There is no significant difference between the confidence level and the well-being index of the person who is in love and the person who has never been in love. (3)self-confidence has a moderating effect on the relationship between the internal and external inclination and people's subjective well-being: in low self-confidence, internal and external inclination to the subjective well-being of a significant predictive role, in the case of high self-confidence, internal and external inclination to the subjective well-being of the predictive effect is not significant. 


\section{References}

[1] Schimmack U, Radhakrishnan P, Oishi S, et al. Culture, personality, and subjective well-being: integrating process models of life satisfaction. J Pers Soc Psychol, 2002, 82(4):582-93.

[2] Yixue Lou, Aiyan Cai, Jimin Yang, et al. Effects of introverted personality on emotional regulation and neural mechanism. Progress of psychological science, 2014, 22(12): 1855-1866.

[3] Canrui Chen, Yanhong Gao, Jo-yong Shen. Meta-analysis of subjective well-being and the characteristics of big five personality. Progression of psychological science. 2012, 20(1): 19-26.

[4] Xiujun Yang, Keqin Kong. Study on the relationship between subjective well-being and personality. Psychological science. 2003, 26(1): 121-123.

[5] Xi Cheng. Research on the relationship between college students' confidence and happiness. Southwest university. 2009.

[6] Zengchong Bi, Xiting Huang. The preparation of questionnaire for young students' confidence. Journal of psychology, 2009, 41(5): 444-453. 